\title{
Contribuições da psiquiatria clássica ao diagnóstico da melancolia: o delírio de negação e o delírio de indignidade ${ }^{1}$
}

\author{
Maria de Fátima Ferreira \\ Vera Lopes Besset
}

Discute-se a respeito da importância que teve a pesquisa empreendida pelos psiquiatras franceses Jules Cotard e Jules Séglas nas primeiras elaborações freudianas acerca da melancolia. No esforço feito por Freud em distinguir as afecções psíquicas, ele leva em consideração os principais conceitos destacados pela psiquiatria clássica: a dor moral, condição para o delírio de indignidade, o mecanismo de auto-acusação e a hemorragia de libido. Busca-se uma articulação entre esses autores. Neste artigo essa retomada é importante para um aprimoramento no diagnóstico da melancolia. Constata-se que a melancolia na contemporaneidade nos remete não somente aos clássicos, mas sobretudo a Freud, em seus primeiros rascunhos.

Palavras-chave: Melancolia, indignidade, autopunição, hemorragia libidinal

1. Este texto é uma versão modificada de parte da dissertação de mestrado da autora Maria de Fátima Ferreira, intitulada: "Melancolia: da identificação narcísica à pura cultura da pulsão de morte", defendida em março/2006, no programa de pós-graduação da Faculdade de Filosofia e Ciências Humanas da Universidade Federal de Minas Gerais - FAFICH-UFMG (Belo Horizonte, MG, Brasil), orientada pela Professora Dra. Ana Cecília Carvalho. Refere-se, igualmente, à tese em andamento, sobre título da tese, da autora, sob orientação da co-autora, desenvolvida no Doutorado em Psicologia da UFRJ. 
Por volta dos anos 1850, muitos estudos já haviam sido feitos pela psiquiatria no campo das perturbações mentais e, no entanto, a melancolia ainda era vista como uma perturbação mental inserida no delírio de perseguição, como uma das formas do delírio de perseguição. O médico francês ErnestCharles Lasègue, do grupo da Salpêtrière, destacou em 1852, de uma maneira inédita, o delírio das perseguições das diversas formas de melancolia. A partir desses estudos é que Jules Cotard, psiquiatra que fazia parte do corpo clínico da Salpêtrière, prosseguiu investigando a afecção melancólica, encontrando, então, três tipos distintos de melancolia: a melancolia simples, a estuporosa e a ansiosa. Ao mesmo tempo em que analisou seus sintomas específicos, separou-a do delírio de perseguição e construiu um arcabouço conceitual que muito favoreceu não só o avanço dessa diferenciação, mas, sobretudo, abriu caminho para o devido recorte psiquiátrico dessa categoria clínica. Vale extrair desse campo conceitual o desenvolvimento da expressão hipocondria moral, uma vez que ela obteve um lugar especial ao longo de suas investigações e daquelas realizadas por pesquisadores que vieram depois.

O ponto de partida para o interesse pelo tema da melancolia é a experiência da autora no Instituto Raul Soares, hospital psiquiátrico por onde circula uma grande variedade de afecções psicopatológicas. Nesse contexto, uma das questões que se apresenta com freqüência é a do diagnóstico diferencial na clínica das psicoses. Essa é uma questão que se renova em cada caso enfrentado, trazendo sempre indagações que se 
traduzem por uma inquietação em busca de investigação, seja no campo teóricoconceitual, seja no campo clínico. Mas uma questão se destaca: O que podem, os psicanalistas presentes em instituição, aprender com a psiquiatria clássica acerca do diagnóstico da melancolia?

$\mathrm{Na}$ melancolia, o problema do diagnóstico revela-se crucial, sobretudo por observar-se, muitas vezes, uma sobreposição de fenômenos, tais como a automutilação, a auto-acusação, podendo chegar ao delírio de negações e de punição ou até mesmo ao suicídio. No entanto, com freqüência, há poucas evidências de fenômenos típicos da psicose. O que aí se sobressai são as passagens ao ato que implicam suicídio, automutilações e auto-recriminações, podendo algumas vezes culminar em uma expectativa delirante de punição.

Diante desse quadro de difícil esclarecimento diagnóstico, a contribuição da psiquiatria clássica é fundamental, especialmente por ter isolado os fenômenos de auto-acusação, o delírio de negação, a dor moral e o delírio de indignidade, próprios da melancolia. Percorrendo a obra de Freud, é possível verificar, em suas primeiras elaborações acerca da melancolia, que sua pesquisa é marcada pelo que os psiquiatras de sua época estavam desenvolvendo. Sobretudo em seus primeiros rascunhos, Freud estava imbuído do saber psiquiátrico de seu tempo. Assim, destaca, desde os rascunhos E e G, elementos fundamentais para o posterior estabelecimento de sua investigação acerca da melancolia. É esse saber sobre a melancolia que nos interessa aqui abordar. Sendo assim, tomaremos como eixo a investigação da melancolia a partir da pesquisa feita pelos psiquiatras clássicos. Nosso intuito é destacar, na pesquisa de Jules Cotard, o momento em que o delírio de negações se separa do delírio de perseguições, e também avançar na investigação sobre o tema do delírio de indignidade isolado por Séglas.

A descrição do fenômeno de base da melancolia, o mecanismo de auto-acusação, pode ser considerada a principal contribuição das investigações da psiquiatria clássica para o estudo e o diagnóstico da melancolia. Tal mecanismo tem um lugar de destaque entre os mecanismos próprios da melancolia, desde a psiquiatria clássica, passando pela obra de Freud, de Lacan e de outros autores contemporâneos da psicanálise.

Nesse contexto, por ter descrito o mecanismo de auto-acusação, Cotard (1882) ocupa uma posição privilegiada. Em seus estudos, baseia-se na seguinte afirmação do psiquiatra e neurologista alemão Wilhelm Griesinger: "Sob a influência do mal-estar moral profundo que constitui o distúrbio psíquico essencial da melancolia, o humor ganha um caráter absolutamente negativo" (p. 153). É, pois, por esse caminho, que Cotard edifica sua investigação acerca do delírio de negação melancólico. Ele busca inspiração, sobretudo, no fator isolado por Griesinger, que diz respeito ao humor negativo do melancólico. A partir daí, en- 
contra razões para estabelecer a distinção entre o delírio de perseguição e o delírio de negação. Assim, ele designa o estado desses doentes como "delírio de negações". Nesse quadro, a disposição negativa é levada ao mais alto grau, no qual o doente apresenta negação de tudo, opondo-se e resistindo a tudo.

\section{Do delírio de perseguição ao delírio de negação}

Com a finalidade de continuar estabelecendo as diferenças entre o delírio de perseguição e o delírio de negação, Cotard (1882) percebeu a importância de distinguir um tipo de hipocondria do quadro geral das hipocondrias. Trata-se, pois, da hipocondria moral. O paciente com delírio de perseguição apresenta traços que vão desde a hipocondria inicial até a megalomania, ao passo que o paciente com delírio de negação apresenta uma profunda depressão, com ansiedade queixosa e um profundo distúrbio da sensibilidade moral. Na origem do delírio de negação está a melancolia com depressão ou estupor e a melancolia agitada ou ansiosa. Não escapou a Cotard um ponto de extrema importância: o delírio não se modifica, mesmo se a manifestação da melancolia se alternar ora em depressão, ora em agitação.

É importante observar que as várias características destacadas por ele, nessa afecção psíquica, estarão presentes nos estudos de Abraham (1911-1924) e de Freud, mas é possível eleger um trecho de suas elaborações que corrobora o que foi dito acima:

Nestas formas predominam a ansiedade (...), os temores, os terrores imaginários, as idéias de culpa, de perdição e de danação; os doentes acusam a si mesmos, eles são incapazes, indignos, fazem a infelicidade e a vergonha de suas famílias, irão prendê-los, condená-los à morte; irão queimá-los ou cortá-los em pedaços. (Cotard, 1882, p. 156)

Isso quer dizer que, diferentemente do delírio de perseguição, na melancolia com delírio de negação, os pacientes acusam a si mesmos, e com isso, eles próprios são seus perseguidores. A singularidade das descrições de Cotard sobre os sintomas melancólicos desses pacientes consiste na delimitação e na extração do traço principal do delírio de negação: o fenômeno de auto-acusação. Conseqüentemente, a distinção entre o delírio de perseguição e o delírio de negação é a manifestação, neste último, do fator da auto-acusação. É claro que no delírio de perseguição também está presente o fenômeno da acusação, mas ele se apresenta de maneira diferente; nesse caso, a acusação é feita a outras pessoas.

A partir do que foi desenvolvido até agora, percebemos que o fenômeno da acusação desempenha um papel fundamental na estruturação do delírio de nega- 
ção. Além desse ponto, é importante ressaltar na melancolia o que o saber psiquiátrico isolou como sendo a predisposição mórbida profunda, que é acompanhada de alteração da sensibilidade com a presença da anestesia. Esse fator da anestesia relacionada à melancolia será tema observado também pelo contemporâneo de Cotard, Jules Séglas, que desenvolverá com mais profundidade esse assunto, e por Freud, em seus primeiros rascunhos.

Com o intuito de construir o caminho por onde evolui o delírio do melancólico que apresenta auto-acusação até chegar ao delírio das negações, Cotard (1882) introduz então, a expressão "hipocondria moral". ${ }^{2}$ Até então, já havia sido feita a oposição entre as duas manifestações da hipocondria: a hipocondria ordinária e a hipocondria moral. Partindo, então, da hipocondria moral é que Cotard pretende fundamentar sua exposição a respeito da evolução do delírio das negações. Nessas condições, o doente que se encontra sob esse domínio não acredita naquilo que o outro afirma de positivo a seu respeito, nem nas manifestações de afeto que lhe são dirigidas. A evolução do delírio melancólico se dá desta maneira:

Os melancólicos ditos sem delírio são atingidos por um delírio triste, tendo como objeto o estado de suas faculdades morais e intelectuais, e já apresentando uma forma negativa evidente. Eles têm vergonha ou mesmo horror de sua própria pessoa e se desesperam pensando que não poderão jamais reencontrar suas faculdades perdidas. Eles lamentam sua inteligência esvaecida, seus sentimentos apagados, sua energia desaparecida. (...) Afirmam que não têm mais coração, afeição por seus parentes e seus amigos, nem mesmo por seus filhos. (p. 159)

Algumas vezes essas manifestações são acompanhadas por idéias de ruína, que se parecem com um delírio negativo, conforme descrito acima. Tornam-se empobrecidos e se apresentam assim para as pessoas que lhe são próximas. Merece destaque o modo pelo qual Cotard se refere ao delírio de negação, opondo-lhe o delírio de perseguição, favorecendo a delimitação do campo conceitual: "Isso é o avesso dos delírios de grandeza em que os doentes se atribuem não só imensas riquezas, como também todos os talentos e todas as capacidades" (ibid.). Nesse sentido a hipocondria moral se opõe à hipocondria ordinária e, mais uma vez, o psiquiatra francês faz uma contraposição entre a

2. Esta expressão não é de Cotard. Foi tomada de empréstimo aos estudos desenvolvidos pelo psiquiatra francês, dr. Jean-Pierre Falret, que em 1882 relacionou a fraqueza moral a uma desordem mental, que é característica da hipocondria moral. 
melancolia e a paranóia: “A hipocondria é para o delírio de ruína, de culpa, de perdição e de negação, aquilo que a hipocondria ordinária é para o delírio das perseguições" (p. 161).

Uma das primeiras negações que se manifesta precocemente no melancólico é a da possibilidade de se curar. Essa negação irá culminar num quadro de negação do mundo exterior e de sua própria existência. Em um grau mais elevado do delírio de negação, quando o delírio de negação já se encontra constituído, ele tem como objeto a própria personalidade do doente ou o mundo exterior.

No caso de serem eles mesmos o objeto, o doente apresenta uma característica bem peculiar, que foi isolada por Baillarger (apud Cotard, 1882, p. 159) ao estudar os paralíticos. Nesses casos, os doentes apresentam-se sem estômago, sem cérebro e sem cabeça e ainda se recusam a comer e não conseguem mais digerir. Freqüentemente retêm suas fezes. Podem se apresentar também com a idéia de que nunca irão morrer. Para Cotard isso se deve ao fato de que, na fase de estupor, os doentes imaginam antes de tudo que estão mortos. O fato de acreditarem que não têm estômago traz uma conseqüência ainda maior: uma recusa à alimentação. Ao passo que, no delírio de perseguição, a recusa de alimentos aparece quando a idéia delirante diz respeito ao fato de acreditarem que alguém possa envenená-los.

Se na hipocondria dos melancólicos há uma prevalência da humildade, da pobreza e da ausência absoluta de valor, na hipocondria dos perseguidos prevalece uma boa imagem de si, com preservação da organização. Nesses, há uma responsabilização do mundo exterior por seus males. Muitas vezes acusam seu médico e chegam ao delírio de perseguição confirmado. Assim, no perseguido, as influências nocivas convergem de fora para dentro de sua pessoa, ao passo que no melancólico a influência nociva parte de dentro dele para o mundo externo.

Cotard (1882) é incisivo em sua investigação, e os elementos que reuniu até aqui parecem recortar bem as distinções entre uma afecção e a outra, caracterizando com clareza o delírio de negação em relação ao delírio de perseguição. No entanto, ele vai nos indicar que, nos casos mais graves da melancolia com delírio de negação, costuma-se detectar a presença de alucinações, "onde os doentes crêem-se envolvidos por chamas (...) e escutam vozes que lhe reprovam seus crimes; a eles lêem sua sentença de morte ou repetem que estão danados" (p. 164-165). Vale ressaltar que na alucinação dos perseguidos os pacientes chegam a dialogar, respondendo a seus interlocutores imaginários. Nos melancólicos, diversamente disso, quando existe alucinação, não se observa o diálogo.

Um fator grave que predomina na melancolia com idéia de danação é o suicídio. Embora nesses quadros os pacientes acreditem já estarem mortos, eles não 
deixam de se destruir: "Uns querem queimar-se, sendo o fogo a única solução; outros querem ser cortados em pedaços e buscam por todos os meios possíveis satisfazer essa necessidade mórbida de mutilações, de destruição, de aniquilamento total" (p. 167). Por isso é que, na clínica da melancolia, o ato de mutilar-se, autoagredir-se e suicidar-se é característica central, mesmo na ausência de fenômenos típicos da psicose. Tais fenômenos são pontos ápices neste estudo, pois irão elucidar, dentro do objetivo aqui proposto, a questão da melancolia em relação ao campo estrutural ao qual ela pertence.

Para os propósitos de cura, Cotard observa que a melancolia é de prognóstico deplorável, embora se refira ao fato de que, com o tratamento, os fenômenos possam diminuir. Mas as idéias delirantes e as negações persistem no mesmo grau. Considera uma certa melhora o fato de que o doente passe a apresentar um quadro de loucura circular ou quadros de acesso ou intermitentes.

A importância de Cotard para nossa pesquisa se situa no modo em que formulou o delírio das negações como avesso do delírio de perseguição. Nesse campo, destaca-se o psiquiatra francês Jules Séglas que, partindo desses estudos, faz avançar a investigação da melancolia, ao extrair da hipocondria moral de Falret, (apud Cotard, 1882, p. 158) um dos principais fenômenos na base desta afecção, que é a dor moral. Esse avanço no estudo da melancolia influenciou pesquisas posteriores realizadas sob a luz da psicanálise. Iremos ver o quanto suas idéias são relevantes, sobretudo para Lacan (1963), que buscou a expressão dor de existir, derivando-a da dor moral de Séglas.

\section{A dor moral e o delírio de indignidade}

Em 1894, Jules Séglas, psiquiatra que fazia parte da Salpêtrière, destacouse ao descrever o quadro melancólico em suas lições clínicas, nas quais apresentou os fenômenos elementares dessa patologia. Entre os fenômenos, todos da maior relevância, encontram-se dois fatores essenciais: a dor moral e o delírio de indignidade. Embora ruidoso e sem se dirigir agressivamente ao outro, o delírio de indignidade constitui fator decisivo na clínica, no que diz respeito à elucidação do diagnóstico. Tais fenômenos constituem o quadro da melancolia simples sem delírio, também designada como melancolia com consciência ou hipocondria moral. São eles: A dor moral, os distúrbios cenestésicos e os distúrbios intelectuais, sendo esses últimos também designados de parada psíquica.

Observa-se que a dor moral é própria da melancolia e já havia sido recortada há séculos, como principal elemento da melancolia. Quanto aos distúrbios fí-

Rev. Latinoam. Psicopat. Fund., São Paulo, v. 11, n. 3, p. 405-419, setembro 2008 
sicos da melancolia, esses são muito variados e Séglas os descreve como: dores sem muita localização, fadiga intensa, palpitações, perda do apetite, constipação, insônia e sonolência. Além desses, existem os distúrbios psíquicos que acompanham os físicos. Esses são denominados de depressão psíquica. Trata-se então de abulia ou apatia, falta de resolução, lentidão dos movimentos, monotonia da fala, falta de cuidados corporais.

Embora outros autores acreditem que é a dor moral que causa a parada psíquica, Séglas é categórico ao afirmar que a dor moral é secundária, ou seja, que ela resulta da derivação da consciência das modificações advindas no exercício das faculdades intelectuais. A cenestesia presente na melancolia é descrita como sendo o sentimento de inexistência do corpo. Nesse aspecto, os distúrbios que sobrevêm em decorrência do início da melancolia atingem as funções orgânicas e culminam em numerosas sensações novas que podem modificar o complexo cenestésico habitual. Séglas localiza o modo em que tais distúrbios se apresentam:

As imagens interiores não são mais adequadas às suas excitações normais; e as sensações, mesmo regularmente transmitidas, não chegam à consciência, senão como um tanto de impressões alarmantes por sua estranheza (Séglas, 1894a, p. 287)

Essa descrição permite compreender o distúrbio da melancolia e pode-se associar ao modo em que Freud descreverá o processo da melancolia como sendo "barrado" em relação ao trabalho interno entre as instâncias psíquicas, por ocasião de uma grande perda.

O processo descrito por Séglas para falar da dor moral se origina do estado cenestésico penoso e do distúrbio do exercício intelectual. Na verdade, a dor moral pode ser resumida em um sentimento de impotência, que se traduz por uma "depressão dolorosa". Nessas condições o melancólico se apresenta com expressões bem particulares em suas atitudes, na sua fisionomia e na mímica, que expressam a sua dor e "traduzem toda a gama das paixões tristes, desde o abatimento e o tédio até a angústia, o terror ou o estupor (p. 290). Tudo isso provoca no melancólico um estado de anestesia e desestesia psíquica: "O melancólico fica insensível às excitações normais, o que faz com que ele se isole cada vez mais do mundo exterior, fechando-se sobre si mesmo. Ele não participa mais do que se passa ao redor dele, tudo lhe parece penoso. (...) Ele vê tudo negro (ibid.).

Segundo Séglas, Griesinger já afirmara que o humor do melancólico é negativo. E, de uma forma bem ampla, vimos em que e como isso se desdobra no delírio das negações, em Cotard. Mas para Séglas, esses são sintomas da melancolia simples, que é designada assim por ser sem delírio ou com consciência. Caso 
o delírio se desenvolva, "ele é uma tentativa de explicação dos fenômenos dolorosos primitivos" (p. 290). Nesse sentido, o delírio é um sintoma secundário na melancolia. Vale destacar o modo como o autor descreve o suicídio melancólico, dizendo que as tentativas, às vezes fracassadas, de se matar, são justificadas pelo fato de que, ao melancólico, falta energia suficiente para despender tal ação:

Sem dúvida, a maioria dos melancólicos rumina durante muito tempo seus projetos de suicídio, inventando todas as espécies de planos (...), mas na realidade somente escondem uma falta absoluta de decisão e de iniciativa, inerente à sua condição mesma de melancólicos (...) eles são incapazes de deslocar energia necessária e fazer um esforço sério para se matar (...) Esta falta de energia nos explica por que, na maioria das vezes, suas tentativas são ridículas ou inacabadas (...), mas elas podem acontecer de repente, sob o golpe de um ataque ansioso, de terror panofóbico, pelo fato de uma impulsão súbita. (p. 295)

Nessa questão do suicídio, Séglas tem razão; a clínica da melancolia nos ensina que é muito raro o melancólico se matar quando está gravemente deprimido. O que se vê é que é preciso coragem para se matar, é preciso despender uma grande quantidade de força para realizar tal ato. É preciso, e isso é algo que a psicanálise indica, um eu mais decidido a impulsionar a ação.

Quanto à melancolia delirante, ela é descrita por Séglas sob variadas formas, cuja característica principal é a humildade e a auto-acusação. Vale lembrar que Cotard já assinalara que a auto-acusação está na base do delírio de negações. A descrição de Cotard é bem parecida com a de Séglas (1984b): "Idéias de ruína, de humilhação, de incapacidade, de auto-acusação, de culpabilidade para com a sociedade, para com Deus, idéias de danação, de perseguição, medo do castigo, de tormentos, do inferno, e, às vezes, idéias mais especiais de negação e de imortalidade" (p. 297).

Mas, como já foi dito, o delírio do melancólico é uma formação secundária, onde, em sua origem principal, estão os fenômenos descritos por Séglas como sendo manifestações da dor moral, que é um dos elementos fundamentais da melancolia. O fenômeno da "parada psíquica" guarda relação com os distúrbios das idéias sobre si mesmo. Como Séglas disse, "as imagens interiores não são mais adequadas", e o que chega à consciência são "impressões alarmantes por sua estranheza" (p. 287). Quanto à auto-acusação e à humildade, Séglas assinala que não são suficientes para o diagnóstico da melancolia, pois estão também presentes em outras manifestações patológicas. Mas, em se tratando da melancolia, elas estão sempre presentes, como fundamentais, integradas na constituição da justificativa delirante.

É, pois, a dor moral, com todos os seus sintomas psíquicos, a causa do delírio na melancolia. Esse se apresenta com um círculo de lamentações bem mo- 
nótono e uma fixação em relação à parada psíquica. Nesse aspecto, Séglas (1984b) já assinala uma distinção com o delírio paranóico: "É bem diferente da sistematização progressiva de outras certezas delirantes" (p. 297). A indignidade presente no melancólico se manifesta através da descrição de suas idéias sobre si mesmo, presentes pelo sentimento de incapacidade, em que o paciente se sente indigno de conviver com outras pessoas e merecedor de todo o mal que o aflige. A descrição do melancólico feita por Séglas merece ser apresentada: "Ele se acredita culpado, indigno de comunicar com seus semelhantes; ele não passa de um animal, uma besta; em suma, uma porcaria. Ele não serve para nada na Terra; melhor seria se estivesse morto" (p. 302-303).

Um dos aspectos relevantes na investigação de Séglas, além de ter descrito a "dor moral" na melancolia, é ter buscado subsídios em seus contemporâneos, tanto em Cotard, quanto em Guislan e Falret, para estabelecer a distinção entre o melancólico e o perseguido: "O melancólico não acusa os outros, ele acusa a si mesmo" (p. 306) O delírio do melancólico tem então uma forma centrífuga, em que ele é o centro do mal e do crime, pois nele vê-se que se inicia na própria pessoa e passa a envolver parentes, amigos e até toda a humanidade. Nessa forma centrífuga, o sujeito, marcado pela humildade, acredita ser nocivo às outras pessoas. Ao passo que, nos perseguidos, as características são diferentes, pois eles acusam os outros, sendo então o seu delírio marcado pela característica centrípeta, na qual o sujeito, orgulhoso, afirma que as outras pessoas é que são nocivas.

Além disso, o melancólico é um humilde, ao passo que o verdadeiro perseguido é um orgulhoso. No primeiro, destaca-se um "delírio de espera" acompanhado por um medo de uma infelicidade lhe chegar por ter provocado algo ruim a alguém: "alguém vai matá-lo, ele será maldito, sua família será arruinada" (p. 302-303). O delírio de indignidade mostra a posição indigna, de humilhação a que o paciente se refere em suas relações pessoais. Isto se manifesta a partir do modo pelo qual o paciente se apresenta. Seu andar é tímido, embotado. Sua voz é sempre baixa. Uma característica que Séglas destaca é a recusa do paciente em cumprimentar o outro. Isso se justifica da seguinte forma:

(...) porque ele não é digno de receber as expressões de estima que lhe dirigimos, que não vale a pena que se ocupe dele. Ele recusa a se assentar no lugar que lhe oferecemos; ou se o deixamos livre, ele escolhe o assento que lhe pareça o menos confortável (...) Se ele recusa os alimentos é porque ele não pode pagá-los e porque descobre que eles são muito suculentos para ele. Se ele trabalha, constrange-se às tarefas as mais repugnantes. (p. 303)

O delírio do melancólico se refere a esse lugar de sujeito do dejeto, de negação de si e do mundo, e é causado pela nocividade que ele representa para os 
outros, ou seja, o delírio do melancólico, monotemático e empobrecido, justifica e desvela seu status abjeto. As idéias delirantes do melancólico são acompanhadas de passividade e de resignação. Muitas vezes essa resignação aparece para o doente portando um sentimento de aniquilação por estar submetido a um poder tão invencível, que o faz se sentir incapaz de lutar. Séglas assinala que "se eles sofrem é porque mereceram devido as suas faltas, é apenas justiça" (p. 304). Tal resignação pode levar o paciente a produzir, inclusive, uma expectativa delirante de punição. Em uma de suas pacientes, Séglas observou que ela se sentia num tribunal, pronta para se dirigir para o palanque de execução. Percebe-se o quanto o delírio de indignidade traz conseqüências e abarca em grande escala o modo como o melancólico convive com as pessoas à sua volta, reiterando sua posição passiva, humilde, inferior e resignada em relação aos outros.

Nessa via é que Lasègue, que já descrevera o delírio de perseguição, o distingue do delírio do melancólico: "O melancólico é um indiciado (prévenu), e o perseguido é um condenado (condamné)" (apud Séglas, 1894b, p. 308). Ser indiciado significa ficar numa posição de espera da sentença, ou seja, da punição e do castigo. ${ }^{3}$ Quanto ao paranóico, esse já recebeu a condenação de morte dada por uma outra pessoa e passa a se sentir perseguido.

Se Cotard descreveu o delírio de negações no qual o sujeito não tem nome, não tem idade, não nasceu, não tem nem pai nem mãe, e, em alguns, eles próprios não existem e não estão vivos, para Séglas, a dor moral apresenta todo um comprometimento para o melancólico, em que temos a descrição da "parada psíquica" como efeito da dor moral. Assim, as idéias desses dois autores convergem para um mesmo plano, tanto do ponto de vista clínico, quanto do ponto de vista conceitual.

Todo esse caminho irá culminar em um esboço bem solidificado dos principais fatores que sustentam, ainda hoje, a clínica diferencial entre a melancolia e a paranóia. Ou seja, o objetivo, ao rastrear o caminho empreendido pelos psiquiatras Cotard e Séglas, é indicar o quanto a investigação de Freud esteve próxima das idéias desses autores, sobre a disposição patológica da melancolia. ${ }^{4}$ Embora Freud não tenha estabelecido a devida estrutura à qual a melancolia se insere, é digno de nota que em seu texto há um predomínio de elementos-chave, isolados pela psiquiatria clássica, que, por sua vez, recortou bem a estrutura da

3. Cf. Freud, em "Luto e melancolia", que irá fazer toda uma descrição detalhada sobre a expectativa delirante de punição (ver p. 275 e 278).

4. Vale conferir os rascunhos "E", "F", "G". Além desses, os textos: "Luto e melancolia" e "O eu e o isso", nos quais Freud recupera a descrição da melancolia, feita pela psiquiatria clássica, e avança em sua investigação sobre o tema, do ponto de vista psicanalítico. 
melancolia dentro do campo da psicose. O que se destaca, na pesquisa de Freud, são os aspectos de empobrecimento do eu e o distúrbio da estima de si, devido à hemorragia libidinal, na melancolia. Para Freud, o modo em que um sujeito responde a uma perda relativa de um objeto, pode ser indicativo de se tratar de uma melancolia. O mecanismo de auto-acusação também é tomado como um fator preponderante e decisivo na elucidação do diagnóstico. Além desse, observa-se na obra freudiana os fenômenos de autopunição, de automutilação, da recusa de alimentos, o delírio de indignidade e inferioridade, como sendo próprios da constituição da melancolia. Freud chegou a designar, para alguns casos de melancolia, a presença maciça da expectativa delirante de punição. Vale indicar, embora não se pretenda aqui trazer as investigações de Freud nem a investigação de Lacan, ${ }^{5}$ o quanto é viva a pesquisa feita pelos psiquiatras franceses e o quão bem ela se insere como chave de leitura na pesquisa contemporânea sobre a melancolia.

Nesse sentido, o percurso empreendido nos primeiros rascunhos de Freud aponta para o fato de que o fenômeno de auto-acusação é princeps no que diz respeito à questão do diagnóstico. Foi através desse fenômeno que Freud distinguiu a melancolia da paranóia, ainda nesses primeiros rascunhos. É nesse sentido que se verifica o quanto a pesquisa feita por Cotard e por Séglas tiveram lugar de destaque na obra de Freud. Em seu esforço para distinguir as afecções psíquicas, Freud buscou sustentação na pesquisa realizada pela psiquiatria francesa. Assim, na clínica contemporânea da melancolia o que se vê é a presença maciça do fenômeno de auto-acusação e auto-recriminações, que se traduzem pelo fato clínico das passagens ao ato de automutilações e por uma intensa dor moral.

É nesse contexto que apontamos os fenômenos de auto-acusação, o delírio de negação, e de indignidade e a hemorragia libidinal, aqui destacados, como indicadores atuais no estabelecimento da especificidade dos fenômenos típicos da melancolia. Ainda hoje, ao nos depararmos com o fato clínico, na contemporaneidade, de sujeitos que se automutilam e/ou apresentam um delírio de indignidade ou um delírio de autopunição e chegam muitas vezes ao suicídio, somos compelidos a buscar, no seio da obra, as contribuições de Séglas, Cotard e de Freud, que parecem-nos de grande valia para a configuração de um diagnóstico de melancolia.

5. Deixaremos a investigação em Freud e em Lacan para uma posterior pesquisa. 
Abrahan, K. (1911/1916/1924). Teoria psicanalítica da libido. Sobre o caráter e o desenvolvimento da libido. Rio de Janeiro: Imago, 1970.

Cotard, J. Du délire des négations. Archives de neurologie, Paris, n. 4, p. 152-170, 1882.

Freud, S. Edição Standard Brasileira das Obras Psicológicas Completas de Sigmund Freud. Rio de Janeiro: Imago, 1988.

. (1893). A etiologia das neuroses. In: Edição Standard Brasileira das Obras Psicológicas Completas de Sigmund Freud. Rio de Janeiro: Imago, 1988. v. I, p. 201-206.

. (1894). Como se origina a angústia? In: Edição Standard Brasileira das Obras Psicológicas Completas de Sigmund Freud. Rio de Janeiro: Imago, 1988. v. I, p. 211-217.

. (1894). Coleção III. In: Edição Standard Brasileira das Obras Psicológicas Completas de Sigmund Freud. Rio de Janeiro: Imago, 1988. v. I, p. 217-221.

. (1894). As neuropsicoses de defesa. In: Edição Standard Brasileira das Obras Psicológicas Completas de Sigmund Freud. Rio de Janeiro: Imago, 1988. v. III, p. 55 a 73.

. (1895). Melancolia. In: Edição Standard Brasileira das Obras Psicológicas Completas de Sigmund Freud. Rio de Janeiro: Imago, 1988. v. I, p. 222-228.

. (1895). Paranóia. In: Edição Standard Brasileira das Obras Psicológicas Completas de Sigmund Freud. Rio de Janeiro: Imago, 1988. v. I, p. 228-234.

. (1896). As neuroses de defesa. In: Edição Standard Brasileira das Obras Psicológicas Completas de Sigmund Freud. Rio de Janeiro: Imago, 1988. v. I, p. 241- 249.

. (1896). Novos comentários sobre as neuropsicoses de defesa. In: Edição Standard Brasileira das Obras Psicológicas Completas de Sigmund Freud. Rio de Janeiro: Imago, 1988. v. III, p. 183- 211.

. (1897). Notas III. In: Edição Standard Brasileira das Obras Psicológicas Completas de Sigmund Freud. Rio de Janeiro: Imago, 1988. v. I, p. 275-277.

. (1915). Luto e melancolia. In: Edição Standard Brasileira das Obras Psicológicas Completas de Sigmund Freud. Rio de Janeiro: Imago, 1988. v. XIV, p. 271-291.

. (1923). O ego e o id. In: Edição Standard Brasileira das Obras Psicológicas Completas de Sigmund Freud. Rio de Janeiro: Imago, 1988. v. XIX, p. 13-83.

LACAN, J. (1963). Kant com Lacan. In: Escritos: Rio de Janeiro: Jorge Zahar, 1993.

SÉGLAs, J. (1887-1894). Leçons cliniques sur les maladies mentales et nerveuses. Paris: Asselin e Houseau, 1895.

. (1894a). De la mélancolie sans délire. In: Leçons cliniques sur les maladies

mentales et nerveuses. Paris: Asselin e Houseau, 1895. p. 282-295.

Rev. Latinoam. Psicopat. Fund., São Paulo, v. 11, n. 3, p. 405-419, setembro 2008 
. (1894b). Le délire dans la mélancolie. In: Leçons cliniques sur les maladies mentales et nerveuses. Paris: Asselin e Houseau, 1895. p. 297-320.

\section{Resumos}

(Contribuciones de la psiquiatría clásica al diagnóstico de la melancolía: el delirio de negación y el delirio de indignidad)

Se discute respecto a la importancia que ha tenido la investigación emprendida por los psiquiatras franceses Jules Cotard y Jules Séglas en las primeras elaboraciones freudianas sobre la melancolía. En su esfuerzo por distinguir las afecciones psíquicas, Freud tiene en cuenta los principales conceptos de la psiquiatría clásica: el dolor moral, la condición para el delirio de indignidad, el mecanismo de autoinculpación y la hemorragia de la libido. En este artículo se vuelve tomar la articulación entre los autores para primorear el diagnóstico de la melancolía. Se constata que la melancolía en la contemporaneidad nos remite no sólo a los clásicos, sino sobretodo a Freud, en sus primeros bosquejos.

Palabras claves: Diagnóstico de la melancolía, indignidad, autoinculpación, hemorragia libidinal

(Contributions de la psychiatrie classique au diagnostique de la mélancolie: le délire de négation et le délire d'indignité)

Nous discutons l'importance qu'a eue la recherche menée par les psychiatres français Jules Cotard et Jules Séglas dans les premières élaborations freudiennes sur la mélancolie. Dans son effort pour distinguer les affections psychiques, Freud prend en compte les principaux concepts mis en évidence par la psychiatrie classique: la douleur morale, condition du délire d'indignité, le mécanisme d'auto-accusation et l'hémorragie de libido. Nous cherchons une articulation entre ces auteurs et dans cet article, cette reprise est importante pour un perfectionnement du diagnostic de la mélancolie. Nous constatons actuellement que la mélancolie nous renvoie non seulement aux classiques, mais, surtout à Freud et à ses premières ébauches.

Mots clés: Diagnostic de la mélancolie, indignité, autopunition, hémorragie libidinale

(Contributions by classical psychiatry to the diagnosis of melancholia: delirium of negation and delirium of indignity)

This article discusses the importance of the research carred out by the French psychiatrists Jules Cotard and Jules Séglas regarding Freud's first considerations on melancholia. In his attempt to distinguish psychic affections, Freud took into consideration the main concepts outlined by classical psychiatry, namely, moral 
suffering, the condition for the delusion of indignity, the mechanism of self-blame, and the hemorrhage of the libido. The article discusses articulations between the two French authors mentioned above, as an important step in better diagnosing melancholia. It is seen that, today, melancholia leads us back not only to the classics, but especially to Freud and his earliest considerations.

Key words: Diagnosis of melancholy, indignity, self-blame, hemorrhage of the libido

Versão inicial recebida em fevereiro de 2007

Versão aprovada para publicação em junho de 2008

\section{Maria de Fátima Ferreira}

Mestre em Psicologia pela FAFICH-UFMG (Universidade Federal de Minas Gerais, Belo Horizonte, MG, Brasil); doutoranda do Programa de Pós-Graduação em Psicologia do IPUFRJ (Universidade Federal do Rio de Janeiro, RJ, Brasil); bolsista Capes; pesquisadora do CLINP (Grupo de Pesquisas 'Clínica Psicanalítica' - UFRJ - Universidade Federal do Rio de Janeiro, RJ, Brasil); membro da equipe de edição da revista Arquivos Brasileiros de Psicologia; psicanalista; aderente da Escola Brasileira de Psicanálise - Seção Minas Gerais (Belo Horizonte, MG, Brasil).

Rua Santa Rita Durão, 321/907 - Funcionários

30140-110 Belo Horizonte, MG, Brasil

e-mail: mfatimaferreira@terra.com.br

\section{VERA LOPES BESSET}

Doutora em Psicologia (Universidade Paris V); professora do Programa de Pós-Graduação em Psicologia do IP-UFRJ (Universidade Federal do Rio de Janeiro, RJ, Brasil); membro pesquisador da Associação Universitária de Pesquisa em Psicopatologia Fundamental (São Paulo, SP, Brasil); coordenadora do CLINP (Grupo de Pesquisas 'Clínica Psicanalítica'UFRJ - Universidade Federal do Rio de Janeiro, RJ, Brasil); editora da revista Arquivos Brasileiros de Psicologia; psicanalista; membro da Escola Brasileira de Psicanálise (Rio de Janeiro, RJ, Brasil) e da Associação Mundial de Psicanálise (Paris, França).

Travessa Euricles de Matos, 28 - Laranjeiras

22240-010 Rio de Janeiro, RJ, Brasil

e-mail: besset@terra.com.br 